
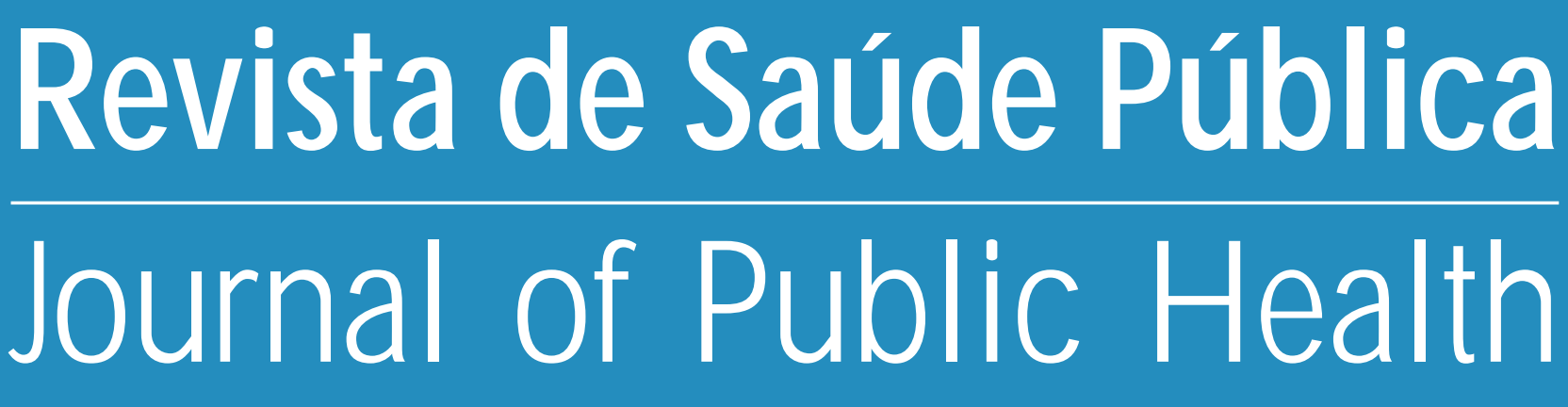

\title{
Dengue: inquérito sorológico pós-epidêmico em zona urbana do Estado de São Paulo (Brasil)
}

Dengue fever: a post-epidemic seroepidemiological survey in an urban setting at a northwestern county of S. Paulo State - Brazil

Virgília L C de Lima, Luiz T M Figueiredo, Heleno R Correa F , 0 dair F Leite, 0 sias Rangel, Alessandra A Vido, Susely S O liveira, Miyoco A O wa, Rita H Carlucci

Superintendência de Controle de Endemias. Campinas, SP - Brasil (VLCL, OFL, OR, AAV, SSO); Departamento de Clínica M édica da Faculdade de Medicina de Ribeirão Preto da Universidade de São Paulo. Ribeirão Preto, SP Brasil (LTMF, MAO, RHC); D epartamento de Medicina Preventiva e Social da Faculdade de Ciências M édicas da Universidade Estadual de Campinas. Campinas, SP - Brasil (HRCF) 


\title{
Dengue: inquérito sorológico pós-epidêmico em zona urbana do Estado de São Paulo (Brasil)* Dengue fever: a post-epidemic sero- epidemiological survey in an urban setting at a northwestern county of S. Paulo State - Brazil
}

\author{
Virgília L C de Lima, Luiz T M Figueiredo, Heleno R Correa F, Odair F Leite, Osias \\ Rangel, Alessandra A Vido, Susely S Oliveira, Miyoco A Owa, Rita H Carlucci \\ Superintendência de Controle de Endemias. Campinas, SP - Brasil (VLCL, OFL, OR, AAV, SSO); \\ Departamento de Clínica Médica da Faculdade de Medicina de Ribeirão Preto da Universidade de São \\ Paulo. Ribeirão Preto, SP - Brasil (LTMF, MAO, RHC); Departamento de Medicina Preventiva e Social da \\ Faculdade de Ciências Médicas da Universidade Estadual de Campinas. Campinas, SP - Brasil (HRCF)
}

\section{Descritores}

Dengue, epidemiologia. Vigilância epidemiológica. Surtos de doenças. Estudos soroepidemiológicos

Keywords

Dengue epidemiology.

Epidemiological surveillance.

Disease outbreaks. Sero-

epidemiological studies

\section{Resumo}

\section{Objetivo}

Avaliar o tamanho real da epidemia sobre dengue ocorrida na zona urbana do Município de Santa Bárbara D’Oeste, SP, Brasil, de abril a junho de 1995.

\section{Métodos}

Foi realizado um inquérito soroepidemiológico pós-epidêmico 5 meses após o final da epidemia da dengue. Foram processados 1.113 soros através de amostragem aleatória domiciliar da população da cidade pesquisada. As taxas de infecção em diferentes partes da cidade foram relacionadas com os graus de infestação por Aedes aegipty e com a quantidade de casos notificados durante a epidemia.

Resultados e Conclusões

Foi encontrada variação concomitante e diretamente proporcional entre as taxas de infecção pelo vírus da dengue, em diferentes partes da cidade, e os graus de infestação domiciliar por Aedes aegipty, bem como em relação ao número de casos notificados durante a epidemia. Encontrou-se prevalência de 630 por 100 mil habitantes, representando valor 15 vezes superior ao de incidência de casos confirmados laboratorialmente durante a epidemia. Através de comparação retrospectiva com dados de notificação compulsória, observou-se que a vigilância epidemiológica não detectou a maioria das pessoas soro-reativas. Apesar disso, notificou grande quantidade de casos que não eram de indivíduos com dengue, tipificando um valor preditivo positivo baixo $(15,6 \%)$ para o diagnóstico clínico de dengue quando o resultado laboratorial (HAI) é tomado como padrão-ouro.

\footnotetext{
Abstract

Objective

The objective of this study was to evaluate the real size of the epidemics registered in the urban area of the county of Santa Bárbara D'Oeste, SP, Brazil, from April to June, 1995. The measurement of the epidemiological validity of the official surveillance system criteria and its positive predicted value were adopted as specific goals.
}

Correspondência para/Correspondence to:

Virgília Luna Castor de Lima- Serviço Regional 5 - Rua São Carlos, 546, Parque Itália

13035-420 Campinas, SP - Brasil

Email: sr05@sucen.sp.gov.br
* Trabalho realizado na Superintendência de Controle de Endemias

Edição subvencionada pela Fapesp (Processo n. 98/13915-5).

Recebido em 21.9.1998. Reapresentado em 3.5.1999. Aprovado em 8.6.1999. 


\begin{abstract}
Methods
A sero-epidemiological survey was carried out over a sample of 1,113 sera from citizens of Santa Barbara D'Oeste, through a systematic random sampling of houses, five months after the end of the epidemics. Infection rates were compared with the infestation indexes by Aedes aegipty and the notified cases amongst the county sections. The importance of submitting patients with clinical suspicion of dengue to laboratory tests was discussed.

Results and Discussion

It was found that infection rates by dengue virus varied in the same direction and proportion as the presence of Aedes aegipty larvae reported by the "Breteau Index", as well as the number of cases reported by the official notifiable diseases surveillance system during the epidemics. A prevalence of 630 by 100 thousand inhabitants was found, a 15-fold rate when compared to the laboratory positive sera from cases detected by the surveillance system during the epidemics. A retrospective comparison with the surveillance reports, using serological results as a gold standard, also showed that the majority of dengue specific serum-positive individuals were not detected during the epidemics, otherwise cases that did not present serological reaction were notified exhibiting a low positive predictive value of clinical diagnosis $(15,6)$.
\end{abstract}

\section{INTRODUÇÃO}

O dengue vem apresentando importância crescente em saúde pública nas últimas décadas. Essa importância se deve ao fato de a partir da década de 50 ter sido identificada a forma grave da doença, a febre hemorrágica do dengue e síndrome de choque do dengue (DH/SCD). Contribuiu também para isso a sua disseminação tanto na forma clássica como na DH/ SCD, com características epidêmicas e edemo-epidêmicas em extensas áreas das regiões tropicais e subtropicais da Ásia, África, Américas, Austrália e Oceania (Johnson et al. ${ }^{9}, 1967$; Halstead ${ }^{8}$, 1990).

No Brasil, à semelhança do que vem ocorrendo em vários países das Américas, nas últimas décadas vêm se registrando epidemias de dengue em vários Estados. Observa-se, ainda, a endemização da doença na maioria dos locais onde ocorre transmissão. As ocorrências de dengue hemorrágico também tornam-se mais freqüentes em concomitância com a circulação dos sorotipos 1 e 2 do vírus em uma mesma área (SUS ${ }^{14}$, 1997; OPS $\left.{ }^{12}, 1997\right)$.

O Estado de São Paulo vem apresentando evolução semelhante. A partir de 1990 tem-se registrado, anualmente, transmissão da doença em alguns de seus municípios, observando-se desde 1995 uma intensificação do problema em relação a maiores coeficientes de incidência e maior número de municípios com transmissão ( $\left.\mathrm{CVE}^{2}, 1996\right)$. Todos os isolamentos de vírus de casos autóctones efetuados no período de 1987 a 1995 mostraram a presença do sorotipo 1. Em 1996 foram registrados casos autóctones de dengue em 99 municípios, tendo sido isolado o sorotipo 2 circulando em dois desses municípios. Temse conseguido submeter a grande maioria dos casos suspeitos de dengue a exame laboratorial. É realizada a técnica de MAC-ELISA para detecção de anticorpos
IgM contra os tipos 1 e 2, em amostra única de soro colhido a partir do quinto dia de doença.

O presente estudo refere-se ao Município de Santa Bárbara D’Oeste, Estado de São Paulo, que apresentou epidemia de dengue no ano de 1995. Faz parte de uma região do Estado que começou a apresentar a presença de infestação por Aedes aegypti desde 1986.

Em 1995 ocorreram as primeiras epidemias de dengue naquela região. Foram atingidos quatro municípios. Apesar dos elevados indicadores de presença de mosquitos nesses municípios, as epidemias foram localizadas e apresentaram coeficientes de incidência baixos se comparados com os registrados em outros Estados e em outros países. Esse comportamento vem sendo observado em outras regiões do Estado.

Santa Bárbara D'Oeste foi um desses quatro municípios. No período de abril a junho de 1995, os serviços de saúde do município notificaram 488 casos de dengue. A maioria teve amostras de sangue coletadas para confirmação diagnóstica por meio da reação de MAC-ELISA. Desses, 57 tiveram resultado positivo. Dois deles foram classificados como "importados" de outros Estados e 55 como autóctones do município. Isto nos fornece um coeficiente de incidência de 37,7 por 100.000 habitantes/ano.

Até o momento, à exceção da epidemia que ocorreu no Município de Ribeirão Preto, que foi o de maiores proporções, não se tem um estudo mais detalhado das epidemias do Estado de São Paulo com levantamento sorológico e discussão a respeito dos possíveis fatores determinantes do quadro epidêmico apresentado.

O presente estudo se propõe a avaliar o tamanho real da epidemia ocorrida no Município de Santa Bárbara D’Oeste, através da detecção de anticorpos no sangue circulante, como também determinar as taxas 
de infecção em diferentes partes da cidade e relacionálas com os grau de infestação de Aedes aegypti e com a quantidade de casos notificados.

Pretende-se também fazer uma discussão a respeito da importância de, em caso de epidemias, submeter os pacientes com suspeita clínica de dengue a exame laboratorial. Do ponto de vista individual, reconhecese a necessidade da confirmação laboratorial do diagnóstico. No entanto, deve-se ter como proposta discutir a abrangência e a utilidade da informação obtida através dos resultados desses exames do ponto vista de saúde coletiva.

Aproveitou-se, ainda, no presente estudo, para se proceder a uma discussão a respeito das dificuldades de análise de um levantamento sorológico para dengue em uma população com antecedentes de vacinação para febre amarela e em região onde há provavelmente circulação de outros flavivírus.

\section{MÉTODOS}

O Município de Santa Bárbara D’Oeste contava no ano de 1995 com uma população de 145.266. Encontrase a $98 \mathrm{~km}$ da capital, fazendo parte de região cuja sede é o Município de Campinas.

Foi realizado um estudo transversal com amostra aleatória de indivíduos, através de sorteio de aglomerados, considerando-se como população-alvo a população total do município. Aos indivíduos sorteados e que aceitaram participar do estudo foram solicitados dados pessoais e informações sobre antecedentes de dengue e de vacinação contra febre amarela e coletada amostra de sangue cujo soro foi posteriormente submetido ao teste de Inibição da Hemaglutinação (HAI).

Foram analisados, também, os dados da epidemia ocorrida em 1995 em relação ao percentual de exames realizados entre casos notificados; em relação ao preenchimento do critério de caso e em relação ao intervalo entre o início dos sintomas e a coleta da amostra de sangue. Foram também calculados, através de uma tabela $2 \times 2$, os valores preditivos positivo e negativo do diagnóstico clínico de dengue para os casos notificados durante a epidemia, tomando como padrão-ouro a confirmação laboratorial dos casos através do teste MAC-ELISA (IgM).

\section{Amostragem}

O tamanho mínimo da amostra foi calculado considerando-se um nível de significância de 5\%, uma prevalência de dengue de $0,04 \%$ /ano ( 57 casos numa população de 145.266 habitantes) e uma variação aceitável para o tamanho da amostra de $0,12 \%$. De acordo com esses cálculos, chegou-se a um tamanho mínimo amostral de 1.059 indivíduos. Para seleção probabilística dos indivíduos que participaram do estudo, foi utilizada a mesma metodologia utilizada pela SUCEN para coleta de larvas voltada para o cálculo do Índice de Breteau (IB). Esse índice, que fornece uma medida indireta da quantidade de mosquitos existente em uma dada área, é representado pela quantidade de recipientes com larvas de mosquitos vetores por 100 casas pesquisadas (Alves et al. ${ }^{1}, 1991$ ). Sucintamente, o município é dividido em setores, calcula-se um tamanho de amostra, em termos de número de casas a serem pesquisadas, para cada setor. Em seguida, são selecionadas, através de sorteio, algumas quadras e nelas algumas casas são pesquisadas para detecção da presença de recipientes com larvas de mosquitos.

O presente estudo foi realizado concomitantemente com a pesquisa para o cálculo do índice de Breteau. Foram utilizadas as mesmas quadras sorteadas para o cálculo desse índice. Para seleção dos participantes do estudo, de início, começou-se o trabalho pela esquina situada a noroeste, visitandose, em sentido horário, alternadamente, uma casa sim e duas não, em cada quadra. Após uma semana de trabalho, observou-se que o número de participantes estava abaixo do esperado. Começouse então a visitar uma casa sim e outra não.

Em cada casa selecionada fazia-se uma visita, durante o dia, na qual era explicado o trabalho a ser realizado e solicitava-se uma autorização por escrito para a coleta do material para exame. Na oportunidade era também distribuída uma carta aos moradores assegurando a utilização de material descartável. Anotava-se, também o endereço da casa, o nome dos moradores, sua idade, sexo e naturalidade, inclusive nas casas cujos moradores se recusaram a receber a próxima visita para a coleta de material. EsSas visitas diurnas foram realizadas pelas visitadoras sanitárias da SUCEN. No final da tarde, era realizada nova visita para coleta do sangue. Aos indivíduos que se submetiam à coleta, eram feitas perguntas sobre antecedente de dengue e de vacinação contra febre amarela, bem como sobre as datas desses eventos.

\section{Exame sorológico}

O sangue era coletado através de punção da polpa digital e embebido em papel de filtro. Em seguida, os papéis eram colocados para secagem, após o que, eram cortados em forma de circunferência com $18 \mathrm{~mm}$ de diâmetro.

Os papéis de filtro contendo os soros adsorvidos eram armazenados $\mathrm{a}-20^{\circ} \mathrm{C}$ até o teste. Os soros foram 
eluídos com solução borato $\mathrm{pH} 9$, na diluição final 1/10. Foram tratados com kaolin para retirada de inibidores inespecíficos da hemaglutinação e adsorvidos com hemácias de ganso para retirada de hemaglutininas inespecíficas. Utilizaram-se antígenos de cérebro de camundongo extraídos pela técnica da sacarose-acetona dos seguintes flavivírus: dengue tipo 1 (estirpe Mochizuki), dengue tipo 2 (estirpe $\mathrm{Ngc}$ ) e febre amarela vacinal (17DD). Os testes de inibição de hemaglutinação foram feitos em microplacas de 96 orifícios e fundo em $\mathrm{U}$, utilizando hemácias de ganso e 8 unidades hemaglutinantes de antígeno em condições de pH6,0 ou 6,1. Inicialmente, triaram-se todos os soros para dengue tipo 1 , na diluição $1 / 10$. Os soros positivos foram posteriormente titulados em testes para os três flavivírus. Soros imunes positivos e negativos foram utilizados nos testes, bem como efetuou-se avaliação simultânea do título hemaglutinante do antígeno.(Shope $\left.{ }^{13}, 1979\right)$.

Os soros, também, eram testados pela técnica de MACELISA para dengue tipo 1 e febre amarela vacinal, utilizando os mesmos antígenos virais utilizados no HAI. (Kuno ${ }^{10}$, 1987).

\section{RESULTADOS}

Das casas sorteadas, 215 (22,5\%) não participaram do estudo por estarem fechadas, por serem estabelecimentos comerciais ou por estarem na casa, na ocasião da visita, apenas crianças. Nas demais casas visitadas, foram coletadas informações sobre sexo, idade e naturalidade de 2.205 pessoas. Os domicílios amostrados resultaram em amostra de 1.113 coletas válidas de soro, sendo excluídos os 574 ausentes na ocasião da coleta $(25,97 \%)$. As recusas tiveram proporção de $23,44 \%$ (518). As análises de sexo, faixa etária e distribuição por setor da cidade não mostraram diferenças significativas entre os que recusaram ou estiveram ausentes e os indivíduos presentes que consentiram em ser submetidos a sangramento para coleta.
Todos os 1.113 soros coletados foram testados pelo teste da inibição da hemaglutinação.

Observou-se, na triagem inicial, 13 soros com anticorpos inibidores da hemaglutinação para dengue tipo 1 (Tabela 1). Não foram detectadas IgM por MACELISA.

Como pode-se observar na Tabela 1, houve reação cruzada entre os antígenos estudados, no soro de 12 desses indivíduos que apresentaram anticorpos inibidores da hemaglutinação. Apenas um indivíduo apresentou soro com teste positivo somente para o dengue tipo 1. Entre os 12 indivíduos com reação cruzada para os antígenos testados, 6 apresentaram titulagem mais elevada para o vírus do dengue tipo 1. Os outros 6 mostraram titulagem mais elevada para o antígeno da vacina contra febre amarela. A maioria dos soros foi negativa para o antígeno do vírus dengue tipo 2. O soro de animal imunizado contra o vírus dengue tipo 2, utilizado como controle, apresentou titulagem mais baixa para o vírus dengue 2 que para os outros antígenos testados.

Dos 1.113 soros testados, 10 correspondiam a indivíduos que referiram ter tido quadro febril durante o período da epidemia. Nenhum deles referiu ter tido diagnóstico clínico ou laboratorial. Separando-se o grupo dos soros reagentes para o HAI e o grupo dos não-reagentes, observa-se que entre os reagentes $23,0 \%$ referiram quadro febril durante a epidemia e que no grupo dos não-reagentes esse percentual cai para $0,6 \%$ e essa diferença foi estatisticamente significativa $(\mathrm{p}=0,00014)$ (Tabela 2). De acordo com a mesma tabela, observa-se que no grupo dos sete soros que apresentaram titulagem maior para o antígeno do vírus tipo 1 , o percentual de indivíduos que referiram quadro febril durante a epidemia sobe para $42,8 \%$, contrapondo-se ao grupo que apresentou titulagem maior para o antígeno da febre amarela, no qual nenhum indivíduo referiu ter tido quadro febril.

Tabela 1 - Indivíduos com anticorpos inibidores da hemaglutinação para dengue tipo 1. Santa Bárbara D’Oeste, 1995.

\begin{tabular}{|c|c|c|c|c|c|c|c|}
\hline \multicolumn{8}{|c|}{ Título HAI (recíproca da diluição) } \\
\hline Pac/Soro & Sexo & $\begin{array}{l}\text { Idade } \\
\text { (anos) }\end{array}$ & Dengue 1 & Dengue 2 & $\begin{array}{c}\text { Febre } \\
\text { amarela }\end{array}$ & $\begin{array}{c}\text { Teve } \\
\text { dengue? }\end{array}$ & Vacina FA \\
\hline LPC/132 & $\mathrm{F}$ & 78 & 20 & negativo & 40 & não & dúvida \\
\hline $\mathrm{VP} / 162$ & M & 31 & 40 & 10 & 20 & $\operatorname{sim}$ & $\operatorname{sim}(92)$ \\
\hline $\mathrm{CP} / 163$ & $\mathrm{~F}$ & 27 & 20 & negativo & 10 & $\operatorname{sim}$ & $\operatorname{sim}(92)$ \\
\hline $\mathrm{DP} / 164$ & $\mathrm{~F}$ & 07 & 40 & 10 & 20 & não & $\operatorname{sim}(92)$ \\
\hline $\mathrm{MC} / 294$ & $\mathrm{~F}$ & 60 & 10 & negativo & 20 & não & $\operatorname{sim}(92)$ \\
\hline $\mathrm{R} / 307$ & $\mathrm{~F}$ & 36 & 10 & negativo & 40 & não & $\operatorname{sim}(92)$ \\
\hline M/398 & $M$ & 84 & 20 & negativo & 40 & não & dúvida \\
\hline $\mathrm{MIB} / 503$ & $\mathrm{~F}$ & 41 & 20 & negativo & 10 & sim & $\operatorname{sim}(92)$ \\
\hline IC/644 & $M$ & 42 & 40 & negativo & 20 & não & dúvida \\
\hline $\mathrm{CSM} / 742$ & $\mathrm{~F}$ & 12 & 20 & negativo & negativo & não & $\operatorname{sim}$ \\
\hline $\mathrm{ESM} / 743$ & $M$ & 14 & 40 & negativo & 10 & não & sim \\
\hline DRA/765 & $\mathrm{F}$ & 32 & 20 & negativo & 80 & não & $\operatorname{sim}(92)$ \\
\hline LS/1004 & $\mathrm{F}$ & 42 & 40 & 10 & 80 & não & $\operatorname{sim}(92)$ \\
\hline Soro imune & DEN 1 & & 160 & 20 & 20 & - & - \\
\hline Soro imune & DEN 2 & & 80 & 20 & 80 & - & - \\
\hline Soro imune & YF & & 20 & 80 & 160 & - & - \\
\hline Soro $C-(B T)$ & & & negativo & negativo & negativo & - & - \\
\hline
\end{tabular}


No que diz respeito ao antecedente de vacinação contra febre amarela, observa-se na Tabela 2 que a porcentagem de casos que afirmaram terem sido vacinados contra essa doença foi maior entre os reagentes por HAI se comparados com os nãoreagentes. No entanto, essa diferença não foi significativa $(\mathrm{p}=0,44)$.

Considerando-se os 13 casos com soros reagentes para os flavivírus testados, temos uma prevalência de $1,17 \%$ entre os examinados. Se considerarmos apenas os sete soros que apresentaram titulagem maior para o vírus dengue 1 , em relação aos títulos para o vírus da febre amarela vacinal, a prevalência é de $0,63 \%$.

As Tabelas 3 e 4 mostram a distribuição dos casos por setor e por bairro. Nessas tabelas foram colocados dados da epidemia para comparação com as informações obtidas nesse levantamento. Observa-se predominância nítida de casos no setor 1 e no bairro Jardim Europa em todos os agrupamentos formados para compor a tabela. Essa predominância fica mais evidente nos casos que apresentaram maior titulagem para o antígeno do vírus dengue tipo 1 no presente estudo e também entre os casos com confirmação laboratorial durante a epidemia.

A grande maioria dos casos, tanto entre os reagentes por HAI como entre os confirmados durante a epidemia, refere-se a residentes em bairros contíguos.

Os achados relativos a faixa etária e sexo não tiveram significância estatística.
Observa-se na Tabela 3 que o índice de Breteau do setor 1 foi, no mês de março - portanto no mês imediatamente anterior a epidemia -, bem mais elevado do que nos outros setores. Há uma clara proporcionalidade entre os índices de Breteau, os casos notificados, os confirmados durante a epidemia e os reagentes para HAI.

Analisando os dados da epidemia, obteve-se que, entre os 488 casos notificados, 403 (82,6\%) tiveram amostras colhidas e examinadas através da técnica de MAC-ELISA. Dos exames realizados, 57 (12,6\%) tiveram resultado positivo. Dos 488 casos notificados, $420(86 \%)$ preencheram a definição de caso clínico de dengue seguido no Estado de São Paulo (paciente que sente febre persistente com duração máxima de 7 dias acompanhada de dois dos seguintes sintomas: cefaléia frontal ou retroocular, mialgia, artralgia, prostração, exantema, manifestações hemorrágicas ligeiras), 52 $(10,85 \%)$ não preenchiam essa definição e $16(3,3 \%)$ casos notificados não tiveram ficha epidemiológica preenchida. Entre os 57 casos com exame laboratorial positivo para dengue, apenas $1(1,7 \%)$ não preenchia o critério de definição clínica de caso suspeito de dengue, apresentando apenas febre e cefaléia.

Observou-se, ainda, que, para $67 \%$ dos casos notificados, coletou-se o sangue entre o $6^{\circ}$ e o $13^{\circ}$ dia após o início dos sintomas. Dez por cento dos casos tiveram coleta de amostra nos 5 primeiros dias de sintomas, $15,3 \%$ tiveram no $14^{\circ}$ e no $30^{\circ}$ dia após o início dos sintomas e 7,4\% após 30 dias do início dos sintomas.

Tabela 2 - Antecedentes de dengue e de vacinação contra febre amarela entre os indivíduos participantes do inquérito sorológico. Santa Bárbara D’Oeste, 1995.

\begin{tabular}{|c|c|c|c|c|c|c|c|c|}
\hline & \multicolumn{4}{|c|}{$\begin{array}{l}\text { Dengue anterior } \\
\text { provável }\end{array}$} & \multicolumn{4}{|c|}{$\begin{array}{l}\text { Vacinação contra F.A } \\
\text { anterior }\end{array}$} \\
\hline & Sim & Não & Subtotal & $\begin{array}{c}\text { Sem } \\
\text { informação }\end{array}$ & $\operatorname{Sim}^{* *}$ & Não** & Duvidoso & Subtotal \\
\hline \multirow[t]{2}{*}{ Reagentes por $\mathrm{HAI}^{*}$} & 03 & 10 & 13 & & 10 & 00 & 03 & 13 \\
\hline & $23,0 \%$ & $76,9 \%$ & $100,0 \%$ & & $76,9 \%$ & $0,0 \%$ & $23,1 \%$ & $100,0 \%$ \\
\hline \multirow[t]{2}{*}{ Não reagentes por $\mathrm{HAl}^{*}$} & 07 & 1.093 & 1.100 & 02 & 637 & 317 & 144 & 1.100 \\
\hline & $0,6 \%$ & $99,4 \%$ & $100,0 \%$ & $0,2 \%$ & $57,9 \%$ & $28,8 \%$ & $13,1 \%$ & $100,0 \%$ \\
\hline \multicolumn{2}{|c|}{ Reagentes por $\mathrm{HAI}$ com maior 03} & 04 & 07 & & 06 & 00 & 01 & 07 \\
\hline título para Dengue 1 & $42,8 \%$ & $57,2 \%$ & $100,0 \%$ & & $85,7 \%$ & $00,0 \%$ & $14,2 \%$ & $100,0 \%$ \\
\hline Reagentes por $\mathrm{HAI}$ com & 00 & 06 & 06 & & 04 & 00 & 02 & 06 \\
\hline maior título para FA & $0 \%$ & $100,0 \%$ & $100,0 \%$ & & $66,6 \%$ & $0 \%$ & $33,3 \%$ & $100,0 \%$ \\
\hline
\end{tabular}

${ }^{*} \mathrm{p}=0,000143 ;$ OR= 46,84 (IC 95\%= 8,19; 248,99)

$* * \mathrm{p}=0,44$

FA - Febre amarela

Tabela 3 - Casos reagentes para HAI no inquérito, casos notificados e confirmados durante a epidemia e índice de Breteau por setores. Santa Bárbara D'Oeste, 1995.

\begin{tabular}{|c|c|c|c|c|c|c|}
\hline Setores & $\begin{array}{c}\text { Reagentes para } \\
\text { HAl no } \\
\text { levantamento } \\
\text { sorológico }\end{array}$ & $\begin{array}{l}\text { Reagentes para } \\
\text { HAI com maior } \\
\text { titulagem para } \\
\text { Dengue } 1\end{array}$ & $\begin{array}{c}\text { Casos } \\
\text { confirmados } \\
\text { na epidemia }\end{array}$ & $\begin{array}{c}\text { Casos } \\
\text { notificados } \\
\text { epidemia }\end{array}$ & $\begin{array}{c}\text { IB - mês } \\
\text { de } \\
\text { março }\end{array}$ & $\begin{array}{c}\text { № de } \\
\text { domicílios }\end{array}$ \\
\hline$\overline{01}$ & 11 & 07 & $52^{*}$ & $301^{*}$ & 21,4 & 18.117 \\
\hline 02 & 00 & 00 & 00 & 61 & 2,0 & 10.636 \\
\hline 03 & 02 & 00 & $03^{*}$ & $118^{*}$ & 12,2 & 15.267 \\
\hline Sem info & & & 02 & 08 & 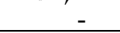 & \\
\hline Total & 13 & 07 & 57 & 488 & - & 44.020 \\
\hline
\end{tabular}


Tabela 4 - Casos reagentes para HAI no inquérito e casos notificados e confirmados durante a epidemia por bairros. Santa Bárbara D’Oeste, 1995.

\begin{tabular}{|c|c|c|c|c|}
\hline Bairros & $\begin{array}{c}\text { Reagentes } \\
\text { para HAI } \\
\text { levantam. } \\
\text { Sorol. }\end{array}$ & $\begin{array}{l}\text { Reagentes } \\
\text { HAI c/maior } \\
\text { titulagem } \\
\text { Dengue } 1\end{array}$ & $\begin{array}{c}\text { Casos } \\
\text { confirmados } \\
\text { epidemia }\end{array}$ & $\begin{array}{c}\text { Casos } \\
\text { notificados } \\
\text { epidemia }\end{array}$ \\
\hline Cidade & 01 & & & 12 \\
\hline Nova & $7,7 \%$ & & & $(2,5 \%)$ \\
\hline Frezzarim & 03 & 01 & 01 & 15 \\
\hline & $23,1 \%$ & $14,2 \%$ & $1,7 \%$ & $(3,1 \%)$ \\
\hline Jardim & 01 & & & 00 \\
\hline $\begin{array}{l}\text { Dulce } \\
\text { Jardim }\end{array}$ & $7,7 \%$ & & & \\
\hline $\begin{array}{l}\text { Jardim } \\
\text { Europa }\end{array}$ & 05 & 05 & 44 & $\begin{array}{c}136 \\
(279 \%\end{array}$ \\
\hline $\begin{array}{l}\text { Europa } \\
\text { Parque }\end{array}$ & $\begin{array}{c}38,5 \% \\
01\end{array}$ & $71,4 \%$ & $77,2 \%$ & $\begin{array}{c}(27,9 \%) \\
12\end{array}$ \\
\hline Zabani & $7,7 \%$ & & & $(2,5 \%)$ \\
\hline Planalto & 01 & 01 & & 05 \\
\hline do Sol & $7,7 \%$ & $14,2 \%$ & & $(1,0 \%)$ \\
\hline Vila Boldrin & $\begin{array}{c}01 \\
7,7 \%\end{array}$ & & & $\begin{array}{c}01 \\
(0,2 \%)\end{array}$ \\
\hline Jardim & & & 01 & 06 \\
\hline Palmeiras & & & $1,7 \%$ & $(1,2 \%)$ \\
\hline Jardim & & & 06 & 32 \\
\hline Pérola & & & $10,5 \%$ & $(6,6 \%)$ \\
\hline Centro & & & $\begin{array}{c}01 \\
1,7 \%\end{array}$ & $\begin{array}{c}15 \\
(3,1 \%)\end{array}$ \\
\hline São & & & 01 & 01 \\
\hline Roque & & & $1,7 \%$ & $(0,2 \%)$ \\
\hline Sartori & & & $\begin{array}{c}02 \\
3,5 \%\end{array}$ & $\begin{array}{c}21 \\
(4,3 \%)\end{array}$ \\
\hline Sem & & & 01 & 06 \\
\hline informação & & & $1,7 \%$ & $(1,2 \%)$ \\
\hline $\begin{array}{l}\text { Jardim } \\
\text { Esmeralda }\end{array}$ & & & & $\begin{array}{c}26 \\
(5,2 \%)\end{array}$ \\
\hline $\begin{array}{l}\text { Demais bairros } \\
\left.\text { (em } \mathrm{n}^{\circ} \text { de } 68\right)\end{array}$ & s 00 & 00 & 00 & $\begin{array}{c}200 \\
(41,0 \%)\end{array}$ \\
\hline Total & $\begin{array}{c}13 \\
100,0 \%\end{array}$ & $\begin{array}{c}07 \\
100,0 \%\end{array}$ & $\begin{array}{c}57 \\
100,0 \%\end{array}$ & $\begin{array}{c}488 \\
100,0 \%\end{array}$ \\
\hline
\end{tabular}

Na Tabela 5 observa-se um valor preditivo positivo baixo para o diagnóstico clínico entre os casos notificados durante a epidemia, enquanto o valor preditivo negativo mostrou-se bem elevado.

\section{DISCUSSÃO}

O presente estudo mostra as dificuldades de interpretação de levantamentos sorológicos realizados para medir a infecção por vírus do dengue em uma população na qual houve, provavelmente, contato com outros flavivírus.

A população de Santa Bárbara D'Oeste foi submetida a vacinação em massa contra febre amarela no ano de

Tabela 5 - Valor preditivo positivo (VP+) e valor preditivo negativo (VP-) do diagnóstico clínico de dengue durante epidemia, Santa Bárbara D’Oeste, 1995.

\begin{tabular}{rll}
\hline \multicolumn{3}{c}{ MAC-ELISA } \\
\hline+
\end{tabular}

\begin{tabular}{lrrr} 
Diag. + & 54 & 292 & 346 \\
Clin. & 1 & 39 & 40 \\
\hline Total & 55 & 331 & $386^{*}$ \\
\hline
\end{tabular}

sensiblidade $54 / 55=98,2 \% \quad \mathrm{VP}+=54 / 346=15,6 \%$ especificidade $39 / 331=11,8 \% \quad \mathrm{VP}-=39 / 40=97,5 \%$ * Foram utilizados para a montagem desta tabela $2 \times 2$ apenas os casos que tinham resultado de exame sorológico e que também possuíam ficha epidemiológica com informação sobre a sintomatologia.
1992 e deve, provavelmente, ter outros flavivírus silvestres circulando, à semelhança de outro município do Estado de São Paulo onde foi realizado estudo que evidenciou essa circulação. (Figueiredo et al. ${ }^{4}, 1986$ ).

Sabe-se das vantagens do teste de inibição da hemaglutinação decorrentes da sua sensibilidade e das facilidades que apresenta para estudos soroepidemiológicos, no entanto, em virtude das reações cruzadas que apresenta entre os anticorpos dos diferentes tipos de dengue e de outros flavivírus, a identificação do vírus infectante torna-se tarefa difícil.

Ao se estar diante de uma resposta sorológica primária à infecção aguda por um dos flavivírus, podese inferir mais facilmente qual o vírus infectante pelos títulos mais altos contra esse em relação aos demais. Nas infecções sorológicas secundárias, a indicação do vírus infectante é mais difícil, podendo-se concluir apenas que a infecção é devida a um flavivírus (OMS ${ }^{11}$, 1987; Theiler et al..$^{15}$, 1973)

Os achados do presente estudo levam a considerar que os casos que se apresentaram reagentes para HAI se tratam de infecções secundárias, pois a maioria referia vacinação anterior contra a febre amarela e, à exceção de um deles, apresentaram reação positiva para os outros vírus testados, evidenciando-se, em 6 deles (46\%), titulagem maior para o antígeno da febre amarela vacinal.

Como visto acima, as reações do tipo secundário seriam ainda mais inespecíficas do que as reações do tipo primário. No entanto, apesar das conclusões baseadas nos resultados laboratoriais não poderem ser muito acuradas, se as inserimos na história epidemiológica do município, os achados do levantamento sorológico fornecem informações úteis.

O município sofreu epidemia documentada através da confirmação de casos por MAC-ELISA. Não foi feito o isolamento do vírus, mas a epidemia de Santa Bárbara fez parte da epidemia da região de Campinas, onde foi isolado o vírus 1. Em todo o Estado de São Paulo no ano de 1995, também, só foi isolado o tipo 1. Este fato poderia justificar o encontro dos seis casos com predominância de anticorpos para o dengue tipo 1 e daquele com anticorpos apenas para esse vírus.

Além disso, a distribuição geográfica dos casos com coincidência dos setores e bairros de maior notificação de casos, de maior número de casos confirmados de dengue durante a epidemia dão respaldo para tirar algumas conclusões. Ressalte-se que essa coincidência fica ainda mais evidente se considerarmos apenas o caso no qual a sorologia só identificou anticorpos para o vírus da dengue tipo 1 e aqueles onde a titulagem foi maior para esse tipo. 
A predominância de história anterior de quadro febril no grupo reagente no teste HAI e com mais evidência no grupo com titulagem de anticorpos predominando para dengue 1 também contribui para a avaliação. É interessante o achado de que a referência à vacinação anterior para febre amarela não representou condição importante para que os soros fossem reagentes para HAI.

Vale a pena, ainda, notar que levantamento sorológico realizado em Cuba em 1983, utilizando a técnica de detecção de anticorpos neutralizantes - que, como se sabe, é bem mais específica-, encontrou prevalência de anticorpos para o vírus do dengue 1 muito próxima à encontrada anteriormente em levantamentos realizados em $1972 \mathrm{e} \mathrm{em}$ 1982, em que foi utilizado teste de inibição da hemaglutinação. Apesar de não ser referida a questão da circulação de outros flavivírus em Cuba, esse achado contribui para a presente avaliação (Guzmán et al. ${ }^{7}, 1990$; Tirado et al. $\left.{ }^{16}, 1984\right)$.

É importante, também, observar que em levantamento sorológico realizado no Município de Ribeirão Preto 10 meses após a epidemia de dengue, através do teste de imunoensaio enzimático com células cultivadas infectadas, nenhum soro apresentou resposta positiva às cepas dos vírus Ilhéus, da encefalite de St.-Louis, Rócio ou da febre amarela. Mesmo considerando-se que a população estudada estava abaixo de 15 anos de idade, este achado merece citação (Figueiredo et al. ${ }^{6}, 1995$ ).

Diante dessas considerações, pode-se concluir que:

1) as infecções por flavivírus não eram recentes ou houve degradação das IgM no papel de filtro, já que não foram detectadas por MACELISA;

2) é provável que o vírus circulante na região tenha sido o da dengue tipo 1 pelo maior número de testes positivos;

3) é provável que a população tenha sido amplamente vacinada contra a febre amarela;

4) é altamente provável que o paciente 742 tenha tido dengue tipo 1 , pois apresentou teste negativo para os outros flavivírus testados; é provável que os pacientes 162, 163, 164, 503, 644 e 743 tenham tido dengue tipo 1, pois apesar de terem reagido também, os títulos apresentados para a febre amarela frente a esse antígeno foram mais baixos;

5) os pacientes 132, 294, 307,398, 765, 1.004 devem ter recébido vacina antiamarílica, pois reagiram com título mais alto para febre amarela;

6) 10 pacientes, entre os reagentes para HAI, referiam ter sido vacinados contra a febre amarela e sete o sabiam, a época (1992), corroborando a alta positividade para febre amarela pelo HAI e mostrando que a infecção por dengue tipo 1 deve ter sido o segundo contato com flavivírus (infecção secundária); e

7) apenas três dos pacientes reagentes referiram ter tido quadro febril durante a epidemia, sugerindo que nos demais a infecção pode ter sido assintomática ou ter apresentação clínica não-característica.

Não se encontrou explicação para o achado do soro de animal imunizado para o vírus tipo 2 ter reagido em títulos mais elevados para os outros vírus testados.

Quanto à avaliação do tamanho da epidemia, encontrou-se que a prevalência encontrada neste estudo foi 2 vezes superior à incidência calculada a partir dos casos notificados durante a epidemia $(0,63 \%$ e $0,33 \%$ respectivamente). Utilizou-se para o cálculo da incidência de casos notificados a população do município no ano de 1995. Foram considerados, para essa análise, apenas os sete casos deste levantamento sorológico, considerados como mais prováveis de terem tido dengue tipo 1.

Levando-se em consideração, agora, apenas os casos notificados durante a epidemia com confirmação laboratorial a superioridade da prevalência encontrada neste levantamento, em relação à incidência notificada, fica mais ostensiva ainda, 15 vezes mais elevada $(0,63 \% \mathrm{e}$ $0,04 \%$ ). No levantamento realizado em Ribeirão Preto em 1992 encontrou-se também prevalência de indivíduos provavelmente infectados duas vezes, superior ao número de casos notificados e 6,6\% mais elevada do que a de casos confirmados (Figueiredo et al. ${ }^{6}, 1995$ ).

Pode-se inferir que cerca de 915 pessoas tiveram dengue durante essa epidemia no município e que a epidemia ocorrida em Santa Bárbara D'Oeste localizou-se em uma área restrita e apresentou baixo índice de infecção. Esse tem sido o comportamento observado nas epidemias ocorridas no Estado de São Paulo. (Figueiredo et al. ${ }^{6}$, 1995; Figueiredo ${ }^{5}$, 1994)

A proporcionalidade encontrada entre os índices de Breteau, o número de casos notificados e confirmados durante a epidemia e o número de casos com soros com anticorpos detectáveis por HAI apontam para a importância da densidade do mosquito vetor para a transmissão da doença.

Quanto à distribuição geográfica, é provável que a epidemia tenha ficado restrita aos bairros situados na região nordeste da cidade, o que alerta para o risco de novas epidemias acometendo outras partes da cidade pelo mesmo sorotipo de vírus e para a possibilidade de $\mathrm{DH} / \mathrm{SCD}$ com introdução de outro sorotipo na área com indivíduos imunes. 
Observando-se a Tabela 4, pode-se sugerir que a notificação de casos de dengue, através da ficha epidemiológica, em determinado bairro, não significa, necessariamente, que esteja havendo transmissão, o que pode ser ilustrado pelo bairro Jardim Esmeralda. Podendo-se dizer, por outro lado, que a concentração de casos notificados, associada à concentração de casos confirmados laboratorialmente em determinado bairro, indica onde a transmissão esteja ocorrendo em maior escala.

Os achados sugerem, como já era esperado, a escassa utilidade da confirmação laboratorial dos casos notificados com finalidade de avaliar o tamanho da epidemia. Tanto o número de casos notificados como o de casos confirmados laboratorialmente durante a epidemia estiveram bem abaixo da prevalência encontrada no levantamento sorológico. Segundo Dietz et al. ${ }^{3}$ (1990), a vigilância epidemiológica do dengue baseada na clínica é inadequada porque as definições clínicas de caso, para o dengue, geralmente, não identificam os casos iniciais e, após a instalação da endemia, a incidência é usualmente superestimada. No caso de Santa Bárbara D’Oeste, a incidência baseada nos casos notificados, quando comparada à prevalência encontrada no levantamento sorológico, como vimos, não foi superestimada, tendo sido, na realidade, subestimada. Ao lado disso, a positividade dos testes laboratoriais realizados nos casos notificados foi baixa. Apenas 12,6\% tiveram resultado positivo. Em outro município do Estado de São Paulo, durante a epidemia, observou-se uma positividade de $40 \%$ entre os exames realizados (Figueiredo $\left.{ }^{5}, 1994\right)$.

A baixa positividade dos testes sorológicos realizados em Santa Bárbara poderia ser decorrente do fato de que, por ocasião da suspeita diagnóstica não se haver respeitado os critérios de definição de caso seguido no Estado ou do fato de que os exames laboratoriais não tivessem sido coletados na data adequada. Averiguando essas possibilidades, observou-se, como já foi visto, que a maioria dos casos notificados teve um diagnóstico clínico de acordo com o critério adotado e também teve a coleta da amostra de sangue na época adequada.

Como foi registrado na Tabela 5, também se constatou um baixo valor preditivo positivo para o diagnóstico clínico de dengue durante a epidemia. Dietz et al. ${ }^{3}$ (1920), em estudo realizado no Rio de Janeiro e em Niterói, encontraram um valor preditivo para o critério de defini- ção de caso clínico de dengue, utilizado no Brasil, de $43 \%$. Valores preditivos positivos baixos para o critério de diagnóstico clínico de dengue são esperados, uma vez que seus sintomas são inespecíficos e que há freqüentemente cocirculação de outras doenças virais na área, observando-se, também, variação da apresentação clínica do dengue de local para local e em períodos diferentes. No caso de Santa Bárbara D’Oeste o valor preditivo do diagnóstico clínico foi ainda mais baixo $(15,6 \%)$.

Para explicar os valores comparativamente mais baixos tanto do percentual de casos positivos entre os notificados como do valor preditivo positivo do diagnóstico clínico encontrados em Santa Bárbara, durante a epidemia, em relação a Ribeirão Preto e ao Rio de Janeiro, talvez se possa aventar a possibilidade de que a incidência mais baixa de casos naquele município, em relação aos outros dois, estaria sendo responsável por este achado. Como lembra Dietz em seu artigo, o valor preditivo positivo e o valor preditivo negativo são dependentes da prevalência da doença.

Podemos, então, dizer que apesar da maioria dos casos notificados terem preenchido o critério clínico de caso suspeito de dengue, e de se ter realizado uma grande quantidade de exames laboratoriais, a maioria resultou negativo. Ao lado disso, não se conseguiu detectar um grande número de casos que adquiriram a infecção no município quando se faz a comparação com o levantamento sorológico.

Estes achados, associados ao valor preditivo negativo elevado do diagnóstico clínico de dengue durante a epidemia, permitem dizer que, quando não se preenche o critério de caso clínico, a probabilidade de se ter dengue é muito baixa. No entanto, quando se preenche esse critério, a probabilidade de se ter dengue é também baixa. Além disso, é elevada a probabilidade de se ter tido dengue e não ter sido detectado pelo sistema de vigilância epidemiológica.

Portanto, se forem levadas em conta essas considerações, conclui-se que vários casos de dengue não estão sendo detectados pela vigilância epidemiológica e, ao lado disso, está se notificando uma grande quantidade de casos que não são de indivíduos com dengue.

\section{REFERÊNCIAS}

1. Alves MCGP, Gurgel SM, Almeida MMCRR. Plano amostral para cálculo de densidade larvária de Aedes aegypti e Aaedes albopictus no Estado de São Paulo, Brasil. Rev Saúde Pública 1991;25:251-6.

2. Centro de Vigilância Epidemiológica. Bol Inform 1996 maio;11(47).

3. Dietz VJ, Gubler DJ, Rigau-Perez JG, Pinheiro F, Schatzmayr HG, Bailey R et al. Epidemic dengue 1 in Brazil, 1986: evaluation of a clinically based dengue surveillance system. Am J Epidemiol 1990;131:693-700.

4. Figueiredo LTM, Rosa APAT, Fiorillo AM. Níveis de anticorpos para arbovírus em indivíduos da região de Ribeirão Preto, SP (Brasil). Rev Saúde Pública 1986;20:204-11. 
5. Figueiredo LTM. Estudos sobre o dengue em Ribeirão Preto 1990-1993. [dissertação] Ribeirão Preto (SP): Faculdade de Medicina de Ribeirão Preto da Universidade de São Paulo; 1994.

6. Figueiredo LTM, Abe Owa M, Carlucci RH, Fabero AL dal, Mello NVd, Capuano DM et al. Encuesta serológica sobre el dengue en Ribeirão Preto, São Paulo, Brasil. Bol Oficina Sanit Panam 1995;118:499-509.

7. Guzmán MG, Kouri GP, Bravo J, Soler M, Vasquez S, Morier L. Dengue hemorrhagic fever in Cuba, 1981: a retrospective seroepidemiologic study. Am J Trop Med Hyg 1990;42:179-84.

8. Halstead SP. Global epidemiology of dengue hemorrhagic fever. Southeast Asian J Trop Med Public Health 1990;21:636-41.

9. Johnson KM, Halstead SB, Cohen SN. Hemorrhagic fever of Southeast Asia and South America: a comparative appraisal. Prog Med Virol 1967;9:105-58.

10. Kuno G, Gómez I, Gubler DJ. Detecting artificial antidengue $\lg M$ immune complexes using an enzyme-linked immunosorbent assay. Am J Trop Med Hyg 1987;36:153-9.
11. Organização Mundial da Saúde. Dengue hemorrágico: diagnóstico, tratamento e controle. Genebra; 1987.

12. Organización Panamericana de La Salud. Resurgimiento del dengue en las Américas. Bol Epidemiol $1997 ; 18(2)$.

13. Shope RE, Sather GE. Arboviruses. In: Lennete EH, Schimidt NJ, editors. Diagnostic procedures for viral, rickettsial and chlamydial infections. 5th ed.

Washington (DC): American Public Health Association; 1979. p. 767-814.

14. SUS. Inf Epidemiol SUS. 1997;6(1).

15. Theiler M, Downs WC. The arthropod-borne viruses of vertebrates. New Haven: Yale University Press; 1973. p. 62-91.

16. Tirado MGG, Flores GK, Gonzalez JB, Silva LC, Ramudo S. Encuesta serológica nacional a virus dengue. Cuba 1982. Rev Cub Med Trop 1984;36:124-31. 